\title{
AN ASSESSMENT OF THE KNOWLEDGE AND SKILL LEVEL IN DENTAL IMPLANT PRACTICE AMONG URBAN DENTIST OF CHENNAI- A CROSS SECTIONAL STUDY
}

\author{
Prabhu R', Rathika Rai², Geetha K. R³, A. G. Prema ${ }^{4}$
}

1 Professor \& Research Scholar, Department of Prosthodontics, Thai Moogambigai Dental College and Hospital, Dr. MGR Educational and Research Institute, Chennai, Tamilnadu, India.

2 Professor and HOD, Department of Prosthodontics, Thai Moogambigai Dental College and Hospital, Dr. MGR Educational and

Research Institute, Chennai, Tamilnadu, India.

3Professor, Department of Prosthodontics, Thai Moogambigai Dental College and Hospital, Dr. MGR Educational and Research Institute, Chennai, Tamilnadu, India.

${ }^{4}$ Postgraduate Student, Department of Prosthodontics, Thai Moogambigai Dental College and Hospital, Dr. MGR Educational and Research Institute, Chennai, Tamilnadu, India.

ABSTRACT
BACKGROUND
The objectives of this study were to assess the awareness and to evaluate the knowledge of dentists of Chennai regarding dental
implant practice.

\section{MATERIALS AND METHODS}

A self-structured questionnaire was distributed to 102 urban general dental practitioners of Chennai. The questionnaire covered general basic information and assessed the knowledge, attitude and practice of GDPs regarding implant dentistry. Descriptive analysis was carried out for the responses.

\section{RESULTS}

The data was analysed using SPSS V.21. and the categorized variables were analysed using chi-square test. P $<0.05$ is considered significant.

\section{CONCLUSION}

After thorough evaluation, it can be concluded that with growing popularity of implants, there is a need to introduce basic implantology at undergraduate level; training programs in implants should be provided or undertaken at postdoctoral level to improve their skills and knowledge and gain confidence to perform the treatment.

\section{KEY WORDS}

Dental Implants, Dentist, Survey.

HOW TO CITE THIS ARTICLE: Prabhu R, Rai R, Geetha KR, et al. An assessment of the knowledge and skill level in dental implant practice among urban dentist of Chennai- a cross sectional study. J. Evolution Med. Dent. Sci. 2019;8(03):206-210, D0I: 10.14260/jemds/2019/45

\section{BACKGROUND}

In dentistry, dental implants have become an indispensable established therapy to replace missing teeth in different clinical situations. Intra-oral use of titanium implants was first suggested in the 1950's. ${ }^{1}$

Because of the continuing emergence of scientific evidence showing high predictability and success rates, dental implants are becoming the standard treatment option for missing teeth in many situations. ${ }^{2}$

Implantology has become an indispensable part of mainstream dentistry, helping dentists to improve the quality of life of their patients. While implant treatment could often be a convenient alternative to conventional treatment options, in certain cases, it is the first treatment of choice for

'Financial or Other Competing Interest': None.

Submission 07-12-2018, Peer Review 07-01-2019,

Acceptance 14-01-2019, Published 21-01-2019.

Corresponding Author:

Dr. Prabhu R, MDS, PhD.

Professor \& Research Scholar, Department of Prosthodontics,

Thai Moogambigai Dental College and Hospital,

Dr. MGR Educational and Research Institute,

Chennai, Tamilnadu, India.

E-mail: drprabhu77@gmail.com

DOI: $10.14260 /$ jemds $/ 2019 / 45$ the rehabilitation of severe functional, anatomical or aesthetic problems arising from tooth loss (1). Dental implantology is the part of dentistry, concerned with the replacement of missing teeth and their supporting structures with artificial prostheses anchored to the jawbone. Modern implants consist of an osseous part that interacts with the bone, a transmucosal component that interacts with the mucosa and then the restoration; this can be a crown or bridge abutment, or anchors for dentures. The materials used commonly for implants include commercially pure titanium, titanium alloys or occasionally ceramic materials (e.g. zirconium dioxide or aluminium oxide).3-8 Surfaces are normally roughened (Microporous) through use of surface preparation (e.g. sand blasting and acid etching) rather than being coated to increase the surface area available for osseointegration (1). Successful implant therapy for patients who receives treatment and the increasing number of patients who depends on their dentists to contribute more decent information, measure that students graduating from dental schools should have solid knowledge and extensive understanding of the implant treatment protocol (2). So many factors influence clinical success and longevity of implants and implant restorations, including; the patient's systemic health, implant site, type of supra-structure, biomechanical considerations, occlusal loads, and oral 
hygiene maintenance. Long-term success and prognosis often depend on successful management of a variety of risk factors (e.g. smoking, diabetes, history of periodontal disease, poor oral hygiene, bruxism, occlusal trauma, etc.) that may be present in each individual case. Also, there are certain complications associated with improper treatment planning, surgical and prosthetic execution, material failure, and maintenance. ${ }^{9}$

For successful implant therapy an understanding of the soft tissue interface with dental implants is much more important. Hence, the dentist needs to be aware of the specific elements of these reactions elicited by different implant materials and surface conditions.

This increased awareness and acceptability of dental implants could be attributed to the fact that the use of partial denture has long been associated with discomfort especially while eating because of denture instability. Other undesirable side-effects associated with the use of dentures include: gum stripping from rough edges of dentures, food packing, infection such as candidiasis, halitosis from poorly maintained dentures, fracture of dentures and poor speech; thus, patients are ready to accept alternative dental restorative options. ${ }^{10-13}$ Fabricated dental Bridges on the other hand, used as alternatives is associated with a compromise of the enamel and dentine of adjacent teeth that is used as abutment for the bridge and recurrent gingivitis could also result from gingival margins that are not well prepared. ${ }^{4}$ Studies among patients that got dental implants in Riyadh reported that about $71 \%$ of the respondents expressed satisfaction with the aesthetics result of the implants as better restorative preferences. ${ }^{5}$ Giedre., et al. in their study on the effects of mandibular fixed implant supported prosthesis reported improvements in deglutition, speech and an increased satisfaction of the implant treatment among edentulous patients. 6

The use of dental implants in the treatment of the edentulous jaws has proved effective in the long term. More recently, the efficacy of dental implants in the treatment of the partially dentate patient has also been demonstrated. Dental implants seem to represent a safe treatment option treated under care and attention of indications, considering anatomical and intra-individual limiting factors, insertion of dental implants. Success rates of $82.9 \%$ after 16 yrs. followup have been reported. To remain competitive, general dental practitioners have to incorporate dental implants as one of the alternatives in their treatment planning. ${ }^{7}$

Use of dental implants over the last decade has increased mainly because of increased awareness about dental implants both in dentists and patients. Nowadays, it is common to see a patient walking into a practice with already implant being placed in him/her or asking for implant placement. Furthermore, dental implant sales continue to rise in developed countries and as public awareness and demands increase, many more general dental practitioners (GDPs) will certainly want to provide dental implant treatment. Therefore, it has become compulsory for the GDPs to be wellacquainted with dental implants.

Implant dentistry procedures is increasingly shifting from specialists to general dental practitioners in the practice setting. ${ }^{4}$ It is one of the rapid increases in global dental implant usage. There is an increase in both the implant manufacturers as well as the number of dentists trained in implant therapy over the past decade. ${ }^{5-8}$

So, the aim of the present study was to know the awareness of dental implant practice among urban dentist of Chennai.

\section{MATERIALS AND METHODS}

A questionnaire based cross-sectional study was made to evaluate the awareness of dental implants of the participants and their opinion about implant treatment.

Study by convenient sampling technique since the duration of the study was less. The patients were selected by convenience sampling technique.

\section{Sampling Unit}

The sampling unit was dentist practicing at urban area of Chennai- Annanagar. (Government, public, private, mission hospitals).

\section{Sampling Method}

A Convenient sampling method were used to select the dentists, currently practicing in private and public sectors. The questionnaire was circulated among the dentists residing in urban area of Chennai. Since the duration of the study was less. The patients were selected by convenience.

A multiple-choice questionnaire was given to 102 urban dental practitioners of Chennai who formed the study group for this study.

In the study group 42 had under graduate qualification and 60 had completed post graduate M.D.S. program of various specialties. These dental practitioners had various years of experience in their practice which was also considered in our questionnaire (Fig. 1). The filled questionnaire was collected, and the results were tabulated and subjected to statistical analysis.

\section{Statistical Analysis}

The qualitative data was expressed by Chi-square test. Fisher's test was used. For statistical analysis, SPSS software version 25.0 was used.

\section{RESULTS}

The data of the cross-sectional study was tabulated, and the results were summarized for each of the 16 questions in the survey.

\begin{tabular}{|c|c|c|c|}
\hline & & Frequency & Percent \\
\hline Valid & BDS & 42 & 41.2 \\
\hline & MDS & 60 & 58.8 \\
\hline \multicolumn{4}{|c|}{ Table 1. Based on Qualification } \\
\hline
\end{tabular}

\begin{tabular}{|c|c|c|}
\hline & & Exp. \\
\hline $\mathrm{N}$ & Valid & 102 \\
\hline Mean & Missing & 0 \\
\hline Median & & 5.9804 \\
\hline Std. Deviation & & 4.0000 \\
\hline Minimum & & 6.12248 \\
\hline Maximum & & 1.00 \\
\hline Percentiles & 25 & 30.00 \\
\hline \multicolumn{2}{|c|}{ Table 2. Experience of Practice } \\
\hline \multicolumn{2}{|c|}{} \\
\hline \multicolumn{2}{|c|}{} \\
\hline
\end{tabular}




\begin{tabular}{|c|c|c|c|c|c|c|c|c|c|}
\hline & & \multicolumn{2}{|c|}{ QUAL } & P \\
\hline & & BDS & MDS & \\
\hline Q1 & Yes & 20 & 55 & 0.001 \\
\hline & & $47.6 \%$ & $91.75 \%$ & \\
\hline & No & 22 & 5 & \\
\hline & & $52.4 \%$ & $8.3 \%$ & \\
\hline Q2 & Yes & 21 & 50 & $<0.001$ \\
\hline & & $50.0 \%$ & $83.3 \%$ & \\
\hline & No & 21 & 10 & \\
\hline & & $50.0 \%$ & $16.7 \%$ & \\
\hline
\end{tabular}

$91.7 \%$ of post graduates are doing implants statistically significant ratio.

Postgraduates prefer to attend courses to seek knowledge about implants comparatively than undergraduates.

$73.8 \%$ of undergraduates interested in assisting treatment than doing. More than $50 \%$ of general dental practitioners said they would not call a specialist, but more than $50 \%$ of postgraduates said would call a specialist for the treatment. On average basic knowledge about implants among both was good, but general dental practitioners assisting than doing implants. Because of ignorance of problems they said not facing problems during procedures and post operatively and getting failures also.

Most of general dental practitioners said not prefer special parameters, eligibility, and prefer implant as a treatment option. Most of them said the implant treatment is safe and economic. Most of the general dental practitioners not satisfied with the implant treatment.

$70-80 \%$ of all the dental practitioners strongly feel the need to practice dental implants in future. Only $20 \%$ of general dental practitioners said no for implementation in future.

\section{DISCUSSION}

Implant dentistry has become an integral part of day to day practice so the appropriate knowledge about diagnostic and therapeutic options are mandatory for all the general dental practitioners. ${ }^{4}$ Use of dental implants over the decade has increased mainly because of increased awareness about implants both in dentists and patients. Nowadays, it is very common to see a patient walking into a practice with already implant being placed in him/her or asking for implant placement. Furthermore, dental implant practice and sales continue to rise in developed countries and as public awareness and demands increase, many more general dental practitioners (GDPs) will certainly want to provide dental implant treatment. Therefore, it has become compulsory for the GDPs to be well-knowledge with dental implants. ${ }^{8}$

Definition of successful implants is constantly changing. Currently, successful implant therapy is defined in terms of both functional and psychosocial acceptance by patients. These patient-centred approaches to the assessment of treatment efficacy appear to be more realistic than physician centred approach.

With rapidly growing use of dental implants, dental graduates may encounter more number of patients with dental implants The maintenance of those implants may then fall upon general dental practitioner. ${ }^{2}$ The dentist should able to differentiate between low $^{-}$, medium-', and high-risk 
situations. They should also know when to refer the patient to specialists as required.

The role of continuous professional development has also been highlighted as a means to improve the overall skills of general dental practitioners toward dental implants. Regardless of didactic training, the single most important factor influencing the attitude of the practitioners toward dental implants was whether or not they sought continuing dental education on the topic. The adverse role of several short "implant courses" that seek to train general practitioners in the placement of dental implants has been documented. However, perhaps, there is a need to stress that training the general practitioner, the management of implant complications, and the long-term maintenance of the implant are as critical as the placement of the implant. ${ }^{14,15}$

Few studies reported that media was the main source of information about the new systems in the implant dentistry. ${ }^{7}$ 8 ,

In our survey, very few GDPs providing the implant treatment. Analysis of the survey revealed that even though many doctors had basic knowledge of dental implants, they were not actively practicing dental implants. The reasons that could be understood from the questionnaire were that they were not confident enough to practice dental implants due to lack of formal training in implant. Those who are doing generally wanted to improve the implant practice in their daily practice by improving their knowledge and skill through attending lectures, advanced courses and clinical hands on exposure. ${ }^{9}$

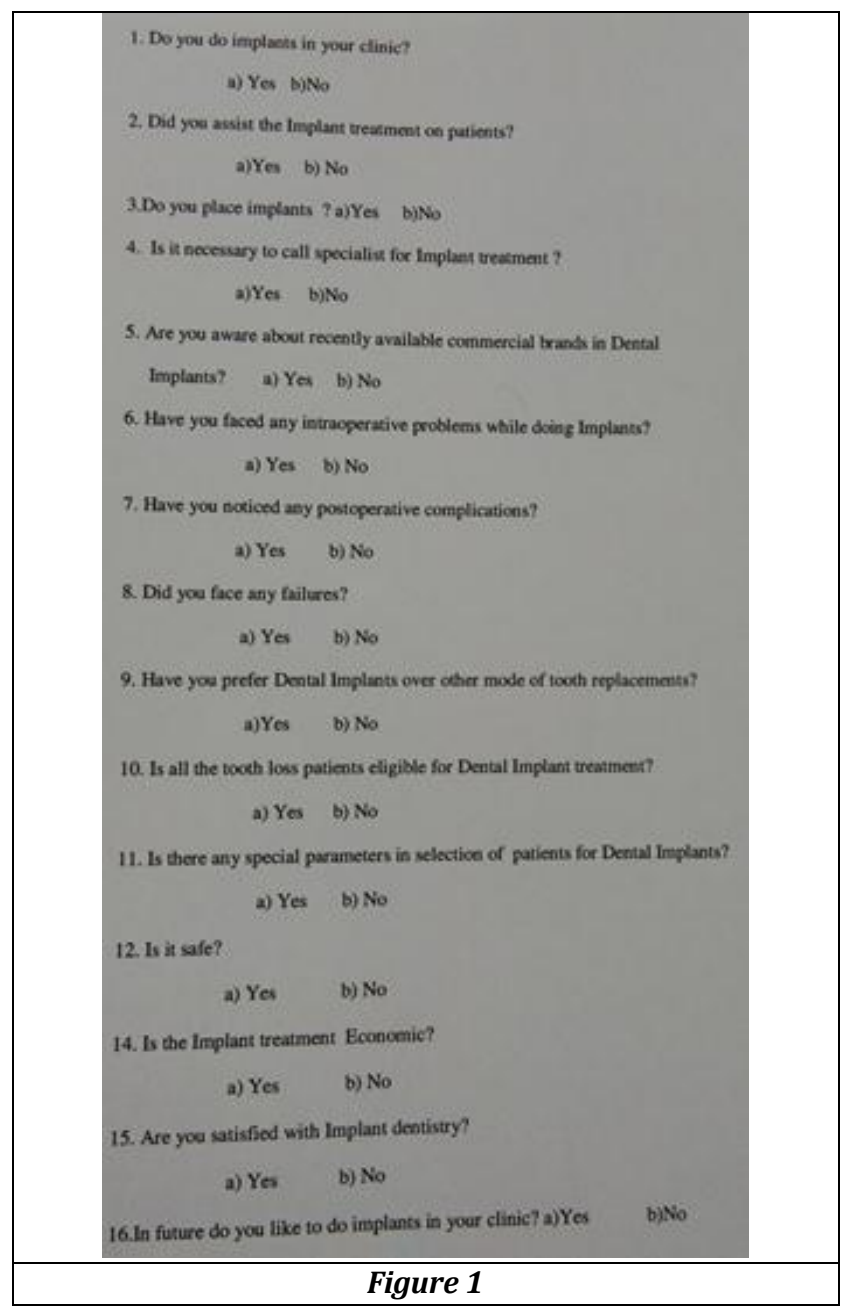

Based on the results obtained from the study.

The qualification plays major role in the practice of implants. This states statistically significant more numbers of post graduates practicing implants than under graduates. ${ }^{16}$

There is a generalized feeling among dental practitioners that they did not have enough didactic or clinical training in dental implants at undergraduate level. ${ }^{17}$

This indicates to introduce basic knowledge about implants in under graduation and also implant training programs in the under graduate level.

Most of the undergraduates are assisting, rather than placing implants. So, they are not facing much problems during surgery and post operatively also, so they need more skill about implants. They were not confident to practice dental implants due to lack of training in under graduation level. With the answer about preference eligibility and special parameters. Even though many of them had basic knowledge of dental implants they need more clinical training at under graduate level.

A study was done in the United Kingdom, by the clinical association of dental implantology; the study showed the majority of implants performed by dentists possessed postgraduate qualifications, although only $2.6 \%$ possessed a degree in dental implantology. The low incidence postgraduate levels in implantology might reflect the relatively limited opportunities for training in the UK.18

Bhageshwar Dhami et $\mathrm{al}^{8}$ stated that $72.7 \%$ had basic knowledge about implant dentistry and $65.5 \%$ were not aware about advance surgical procedures like sinus lift, guided bone regeneration All the GDPs were interested in more training and education in dental implants and $95.5 \%$ of them would like to incorporate dental implant treatment in their practice in future. Where we observed more than $70 \%$ of general dental practitioners had basic knowledge about implant dentistry. ${ }^{10,11}$

Nasser Mansour Assery et al ${ }^{19}$ concluded that, Dentists actively participated in dental implantology workshops had a higher tendency to answer correctly compared to dentists who were given didactic courses in their undergraduate studies and associated with hands-on training. This handson training in the undergraduate studies would result in a better understanding of dental implants, its complications, and management of difficult cases of dental implants.

Bueno $\mathrm{R}$ et $\mathrm{al}^{20}$ study recently showed that the clinical or didactic environment in which the student is trained significantly alters his/her perception of clinical situation.

Haghighat et al. ${ }^{14,15}$ stated that dentists in Isfahan did not have proper knowledge about dental implants, with general dental practitioners being less knowledgeable than specialists. In a similar survey done by According to Shah, et al. ${ }^{18}$ an acceptable response rate of $65.33 \%$ was reported about implant awareness and result shows $41.8 \%$ of dentists with postgraduate qualification, in this survey more than $90 \%$ of dentists with postgraduate qualification.

\section{Limitation of the Study}

Due to short duration of study, convenience technique was followed. Thus, sample was also calculated by convenience. The results of the study cannot be generalised due to the potential bias resulting and sample size estimation. 


\section{CONCLUSION}

After thorough evaluation, it can be concluded that with growing popularity of implants, there is a need to introduce basic implantology at undergraduate level; training programs in implants should be provided or undertaken at postdoctoral level to improve their skills and knowledge and gain confidence to perform the treatment.

\section{REFERENCES}

[1] Hicklin SP, Albrektsson T, Hämmerle CH. Theoretical knowledge in implant dentistry for undergraduate students. Eur J Dent Educ 2009;13 Suppl 1:25-35.

[2] Basutkar NA. Assessment of knowledge related to implant dentistry in dental practitioners of north Karnataka region, India. Journal of Dental Implants 2013;3(1):26-8.

[3] Mgbeokwere U, Okoye L, Ekwueme O. A survey of the knowledge of dental implants as a choice in treatment of edentulous jaws among health workers in Government Dental Clinics in Enugu. Ann Med Health Sci Res 2011;1(1):91-6.

[4] Schenk RK, Buser D. Osseointegration: a reality. Periodontol 2000 1998;17(1):22-35.

[5] Al-Hamdan K, Meshrif H. Patients' satisfaction with dental implants in Riyadh, Saudi Arabia. Saudi Dent J 2007;19(2):6-11.

[6] Gibson RL, Barclay CW. Dental implantology education: a survey of opinion and experience of 106 general dental practitioners. British Dental Journal 2006;201(6):367-70.

[7] Ng PC, Pow EH, Ching SH, et al. Dental implant practice among Hong Kong general dental practitioners in 2004 and 2008. Implant Dent 2011;20(1):95-105.

[8] Dhami B, Shrestha P, Lamichhane B, et al. Dental implants and general dental practitioners of Nepal: a study of existing knowledge and need for further education. Journal of College of Medical SciencesNepal 2017;13(1):212-5.

[9] KhalfAllah EMA, Aljabry AS. Assessment of knowledge of peri-implant diseases and implant maintenance programs among dentists in three implantology centers in Khartoum-Sudan. IOSR Journal of Dental and Medical Sciences 2017;16(10):15-22.
[10] Smith DE, Zarb GA. Criteria for success of osseointegrated endosseous implants. J Prosthet Dent 1989;62(5):567-72.

[11] Al-Omiri MK, Abu Hantash RO, Abu Yunis M, et al. Relationship between personality and impacts of implant treatment on daily living. Clin Implant Dent Relat Res 2012;14 Suppl 1:e2-10.

[12] Baracat LF, Teixeira AM, dos Santos MB, et al. Patients' expectations before and evaluation after dental implant therapy. Clin Implant Dent Relat Res 2011;13(2):141-5.

[13] Bryant SR, MacDonald-Jankowski D, Kim K. Does the type of implant prosthesis affect outcomes for completely edentulous arch? Int J Oral Maxillofac Implants 2007;22 Suppl:117-39.

[14] Pournasrollah A, Negahdari R, Pakdel SM. Evaluation of the knowledge of general dental practitioners in Tabriz about the implant treatment planning. Advances in Bioscience and Clinical Medicine 2015;3(3):24-31.

[15] Haghighat A, Bonakdariyan M, Ghaffari M. Evaluation of Isfahan dental practitioners' awareness about dental implants. Isf Den J 2009;6:493-9.

[16] Klugman R, Sgan-Cohen H, Stern N. A survey of dentists practicing implant dentistry in Israel. The Journal of Prosthetic Dentistry 1990;64(4):473-8.

[17] Watson MT. Implant dentistry: a 10-year retrospective report. Dent Prod Rep 1996;30:26-32.

[18] Shah RJ, Shah SG, Patel GC. Trends in implant dentistry among private dental practitioners of Gujarat: a survey. Journal of Dental Implants 2014;4(1):48-52.

[19] Assery NM, Shaheen R, Taifi M, et al. Management of dental implant complications among general dental practitioners in Riyadh, Saudi Arabia. Saudi Journal of Oral Sciences 2018;5(1):17-21.

[20] Pineda K, Bueno R, Alvarado C, et al. Influence of academic training in endodontics and implantology on decision-making in undergraduate students. Australian Endodontic Journal 2018;44(1):40-5. 